\title{
A GÊNESE DE CHAVANTES - SP ATÉ A PRIMEIRA METADE DO SÉCULO XX: RELAÇÃO RURAL-URBANO
}

\author{
THE GENESIS OF CHAVANTES - SP UNTIL THE FIRST HALF OF THE \\ 20TH CENTURY: RURAL-URBAN RELATION
}

\section{LA GENÈSE DE CHAVANTES - SP JUSQU'AU PREMIÈRE MOITIÉ DU 20ÈME SIÈCLE: RELATION RURAL-URBAIN}

Franciele Ferreira Dias

\author{
Doutora em Geografia pela UEL. Professora substituta no curso de licenciatura e \\ bacharelado em Geografia na Unesp (Campus de Ourinhos). \\ E-mail: franciele.ferreira-dias@unesp.br
}

\section{RESUMO}

O objetivo do trabalho é discutir a gênese de Chavantes até a primeira metade do século $\mathrm{XX}$, momento de ruptura, em decorrência de mudanças nos processos produtivos e da intensificação do processo de urbanização, trazendo novos papeis à cidade perante o rural. Considera-se nesse trabalho os elementos que influenciaram a gênese do município de Chavantes: a expansão dos trilhos da E.F. Sorocabana e dos cafeeiros em direção ao Centro-Oeste Paulista, no início do século XX. Para a realização do trabalho, consultouse a bibliografia relativa à história de Chavantes e de Santa Cruz do Rio Pardo (do qual Chavantes foi distrito) bem como dados censitários, com o intuito principalmente, de analisar elementos atrelados ao rural-urbano, durante o período citado. Foi realizado um levantamento de campo em junho de 2018, com o objetivo de coletar informações acerca dos aspectos não esclarecidos pela bibliografia consultada. Compreendeu-se que, a origem de Chavantes relaciona-se diretamente à expansão cafeeira e a inserção da ferrovia, bem como o desenvolvimento do município, no período analisado, está atrelado aos dois elementos citados, importantes na relação rural-urbana.

Palavras-chave: Chavantes; Gênese; Dinâmica Rural-Urbana; Café, Ferrovia.

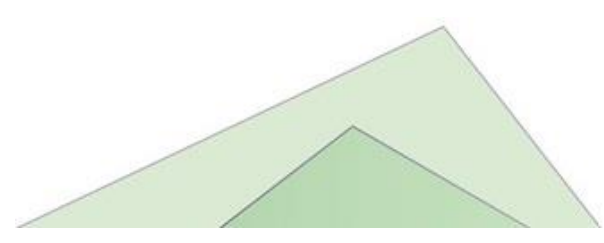




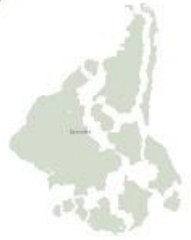

\section{ABSTRACT}

The objective of the work is to present the rural-urban dynamics of Chavantes until the first half of the twentieth century, a moment of rupture due to changes in the productive processes and the intensification of urbanization, bringing new roles to the town before the rural area. This work considers the following elements that influenced the genesis of the municipality of Chavantes: the trails expansion of the E.F. Sorocabana (Sorocabana Railway) and the coffee trees towards the central-west region of São Paulo at the beginning of the 20th century. To carry out the work, regarding the understanding of the town genesis, we consulted the bibliography on the history of Chavantes and Santa Cruz do Rio Pardo (of which Chavantes was a former district) as well as census data, with the main purpose of analyzing urban-rural elements during the mentioned period. A field survey was carried out in June 2018, to collect information about historical aspects and the rural-urban dynamics, which were not clarified by the bibliography consulted. It was understood that the origin of Chavantes is directly related to the coffee expansion and the insertion of the railway, as well as that the development of the municipality in the analyzed period is linked to the two elements mentioned, which are important in the ruralurban relation.

Keywords: Chavantes; Genesis; Rural-Urban Relation; Coffee; Railway.

\section{RÉSUMÉ}

L'objectif du travail est de discuter de la genèse de Chavantes jusqu'à la première moitié du XXe siècle, une période de rupture, due aux changements dans les processus productifs et à l'intensification du processus d'urbanisation, apportant de nouveaux rôles à la ville avant le rural. Dans ce travail, les éléments qui ont influencé la genèse de la commune de Chavantes sont considérés: l'extension des sentiers de E.F. Sorocabana et des caféiers vers le Midwest de São Paulo, au début du 20ème siècle. Pour mener à bien les travaux, nous avons consulté la bibliographie relative à l'histoire de Chavantes et Santa Cruz do Rio Pardo (etait le district du Chavantes) ainsi que des données de recensement, dans le but principal d'analyser des éléments liés au rural-urbain, lors la période citée. Une enquête de terrain a été réalisée en juin 2018, afin de collecter des informations sur des aspects non clarifiés par la bibliographie consultée. Il a été entendu que l'origine de Chavantes est directement liée à l'expansion du café et l'insertion du chemin de fer, ainsi que le développement de la commune, dans la période analysée, est lié aux deux éléments mentionnés, importants dans la relation rural-urbain.

Mots-clés: Chavantes, Genèse, Dynamique rurale-urbaine, Café, Chemin de fer.

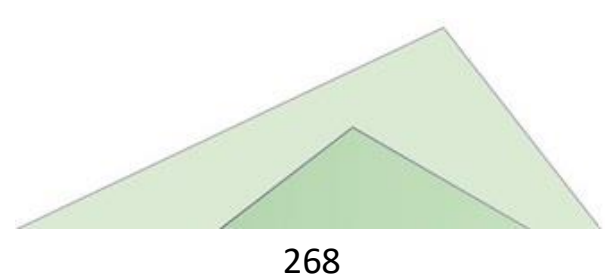




\section{INTRODUÇÃO}

O trabalho cujo objeto de estudo é a gênese de Chavantes-SP até a metade do século XX, considerando as relações econômicas rurais-urbanas, relaciona-se à parcela dos resultados obtidos na tese de doutoramento da autora (FERREIRA DIAS, 2019).

Justifica-se a realização desse trabalho como uma forma de compreender qual o papel desempenhado pelas pequenas cidades em um contexto em que as atividades econômicas eram mormente desenvolvidas no âmbito rural e no qual a cidade desempenhava papel complementar, sendo suporte necessário à economia municipal.

Parte-se da compreensão inerente ao rural e urbano, considerando os equipamentos e infraestruturas presentes no espaço urbano, de modo que aquilo que não se enquadra nessa esfera, é rural, além dos aspectos políticos-administrativos (ALVES e VALE, 2013). Para a realização do trabalho, quanto à compreensão da gênese da cidade e das relações que envolviam o rural e o urbano no período analisado, consultou-se a bibliografia relativa à história de Chavantes e de Santa Cruz do Rio Pardo (pois Chavantes era distrito pertencente ao mesmo) e dados censitários.

O objetivo principal foi compreender a gênese da cidade de Chavantes, associado às relações econômicas que envolviam o rural e o urbano durante a primeira metade do século $\mathrm{XX}$, período em que ocorreu a gênese e a consolidação do núcleo urbano estudado. Os objetivos específicos foram: 1) Apresentar a gênese de Chavantes, associado ao papel da ferrovia e da expansão cafeeira, os quais contribuíram para a criação e consolidação desse núcleo urbano; 2) Associar a queda da produção cafeeira com a intensificação do processo de urbanização desse município e o desenvolvimento das atividades econômicas urbanas.

De acordo com Santos (2013), o Brasil foi durante séculos, um grande arquipélago cujos subespaços evoluíram segundo lógicas próprias relacionadas na maioria das vezes com o mundo exterior, existindo poucas relações econômicas internas.

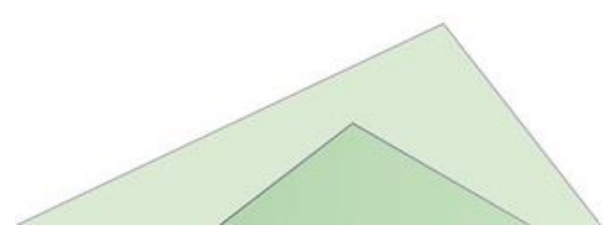


Nesse sentido, a criação de cidades se deu vagarosamente, com a intensificação apenas a partir do início do século XX, principalmente em razão do desenvolvimento e consolidação dos meios de transportes.

No estado de São Paulo a gênese das cidades está relacionada à inserção da ferrovia, amplamente difundida, servindo inicialmente como elemento conector entre essas cidades, funcionando como meio de transporte para a população, escoamento da produção e para a difusão de informações.

A partir das ferrovias, tem-se a consolidação de parte dos núcleos urbanos paulistas, principalmente no Centro-Oeste Paulista, onde localiza-se Chavantes (SEADE, 2011). O Centro-Oeste Paulista era composto por inúmeros latifúndios, que durante o período das sesmarias não progrediram, permanecendo povoações como Lençóis Paulista, Botucatu, São Manuel, Jaú, Águas de Santa Bárbara e Santa Cruz do Rio Pardo, do qual Chavantes manteve-se como distrito até 1922 (PRADO, 2012). Assim, até a efetivação do complexo cafeeiro paulista, o Centro-Oeste Paulista não estava efetivamente ocupado, apresentando ocupação dispersa e algumas poucas atividades agrícolas (PRADO, 1999);(WAIBEL, 1955).

Conforme se discute nesse artigo, o cultivo do café para fins de exportação resultava em relações econômicas que envolviam o rural e o urbano de forma relativamente complexa, na medida que a cidade ofertava os bens e serviços necessários à produção cafeeira. Por outro lado, a ferrovia servia tanto para o escoamento dessa produção quanto para o transporte de passageiros.

Presentemente, Chavantes conta 12.223 habitantes (IBGE, 2018) e pauta a economia no cultivo de cana-de-açúcar, nas indústrias produtoras de equipamentos industriais (Paletizadora Chavantes), indústria de apoio ao setor sucroalcoleiro (Biomassa BR), construção civil (Arameficio Chavantes) e metalurgia (Indústria e Comércio de Martelos Chavantes, Indústria Filcer). Há ainda o setor terciário, destacando-se à prestação de serviços ao setor industrial mencionado. A figura 1 apresenta a localização de Chavantes, a 376 km da capital São Paulo. 
Figura 1: Localização de Chavantes

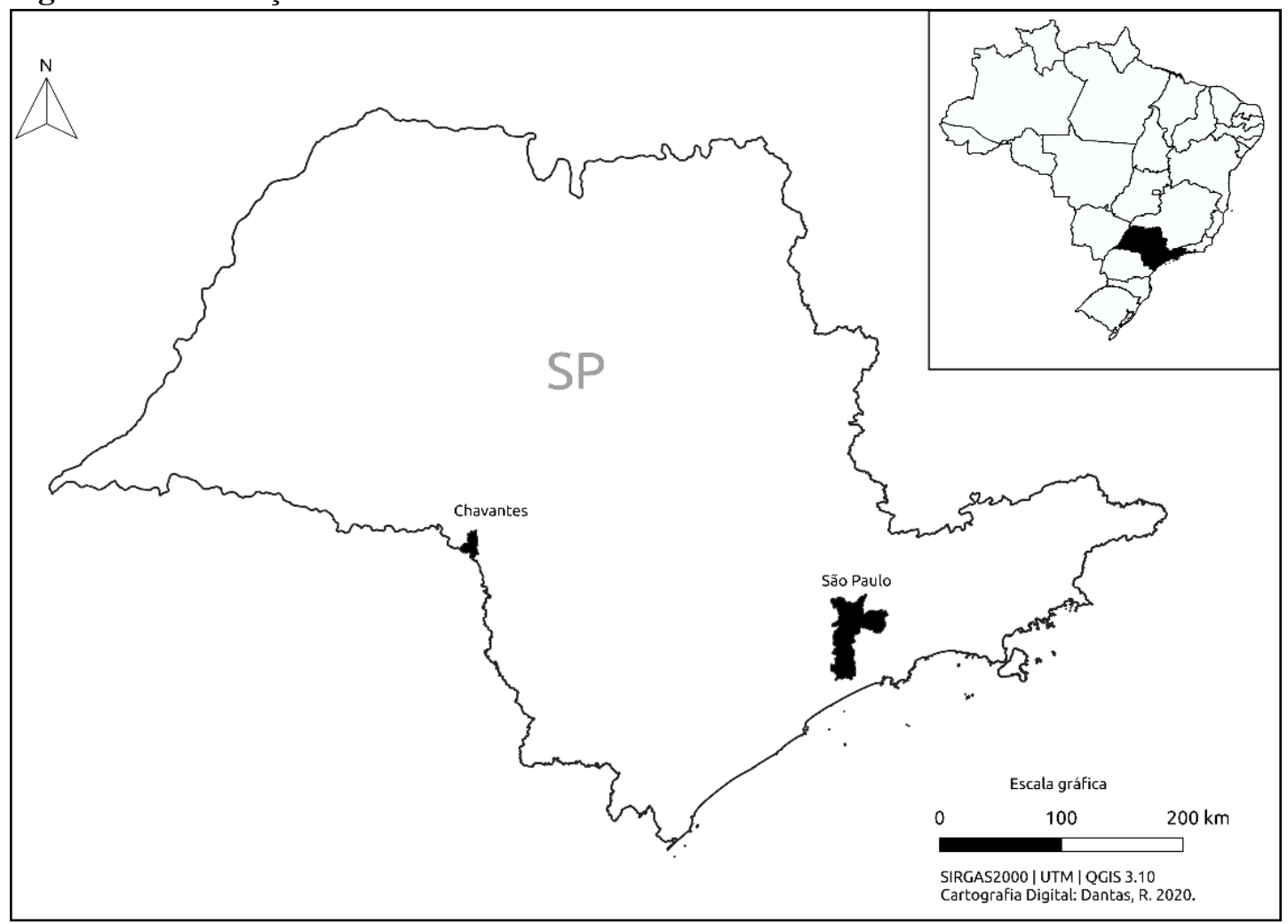

Organização: A autora.

\section{A GÊNESE DE CHAVANTES}

Conforme Prado (1999) o princípio da ocupação do estado de São Paulo, deuse na primeira metade do século XVI, através do povoamento do litoral e arredores da capital São Paulo. Porém, até meados do século XVIII, o território paulista era fracamente ocupado, restrito às povoações onde desenvolvia-se lugares de passagem, comércio de mercadorias e/ou controle administrativo da colônia, não existindo atividades econômicas relevantes e urbanização efetiva. Até a primeira metade do século XIX, o povoamento permanecia restrito ao litoral, região da capital paulista, Vale do Paraíba e parte da divisa com o estado de Minas Gerais. O Centro-Oeste Paulista, era, do ponto de vista do 
processo de incorporação de terra, relativo ao sistema capitalista e a criação de cidades, pouco habitado.

O interior do estado, embora praticamente desabitado, já era conhecido por alguns grupos que se dedicavam à atividade seminômade, com alguma cooperação ocasional. Esse povoamento disperso era manifesto através de uma população rarefeita espalhada pelo território, dificultando a fundação de novas povoações. Porém, devido à existência de extensas áreas com terras férteis, era possível a renovação do plantio, sem a necessidade de comprar outra terra e, portanto, expandir a ocupação por novas partes do estado paulista (CANDIDO, 1979).

No último decênio do século XVIII, a decadência da atividade mineradora em Minas Gerais levou à migração, inicialmente, em direção ao norte do estado de São Paulo, nas proximidades de Ribeirão Preto e posteriormente para o Centro-Oeste Paulista. Esses migrantes dedicavam-se à criação de gado bovino e culturas de subsistência, pois a distância dos principais centros urbanos e a falta de meios de transportes e vias de acesso inviabilizava atividades econômicas mais complexas. Até a primeira metade do século XIX, o Centro-Oeste Paulista era pouco conhecido, sendo um sertão habitado por indígenas e alguns caboclos dispersos nas proximidades dos grandes rios, dentre eles o Paranapanema e o Pardo (MONBEIG, 1984).

Para Junqueira (1994) Santa Cruz do Rio Pardo, município do qual Chavantes era distrito, foi área de passagem de exploradores que buscavam adentrar o sertão paulista, através dos cursos dos rios navegáveis Turvo e Pardo e dos espigões, que facilitavam parcialmente esses deslocamentos. O início da ocupação desse município foi motivado por agricultores mineiros, que se estabeleceram às margens do Rio Pardo durante a década de 1850, sendo a fundação oficial em 1872.

Desse modo, antes da expansão da marcha do café em direção ao CentroOeste Paulista, Santa Cruz do Rio Pardo e outras povoações foram criadas, a exemplo de Águas de Santa Bárbara (1858), Botucatu (1846), Lençóis Paulista (1858) e São Pedro do 
Turvo (1876), configurando o limite da ocupação em direção ao oeste paulista, caracterizando-se pela agricultura de subsistência e restrita pecuária (MONBEIG, 1984).

O fator fundamental para a ocupação do Centro-Oeste paulista, até então fracamente habitado e a gênese da maioria dos núcleos urbanos, dentre eles, Chavantes, atrela-se à expansão dos cafeeiros pelo estado, após a segunda metade do século XIX (PRADO, 1999).

Embora o café tenha sido plantado em diferentes partes ${ }^{1}$ do Brasil, o êxito ocorreu a partir do aumento da demanda internacional, em especial quanto à popularização dessa bebida nos Estados Unidos. O estado de São Paulo tornou-se o principal produtor brasileiro por reunir uma série de características necessárias à produção comercial do café: 1) declividade do solo menos abrupta; 2) clima adequado com chuvas bem distribuídas; 3) boa qualidade de solo; 4) capital para financiar a produção; 5) $\mathrm{O}$ cultivo do café era voltado para fins de exportação, atendendo à crescente demanda externa; 6) A produção era realizada em grandes propriedades, absorvendo a ampla mão-de-obra imigrante recém-chegada ao estado (SILVA, 1985).

Apesar do Vale do Paraíba ter sido o percursor e principal produtor de café no estado de São Paulo, o exaurimento dos recursos naturais locais direcionou a produção para o centro e norte do estado, incorporando novas terras e criando povoações. Ao atingir o norte do estado de São Paulo, surgiu o problema da distância dos cafeeiros quanto ao escoamento da produção para exportação, realizado através do porto de Santos (SP). O problema foi resolvido através da construção das ferrovias (CANO, 2007).

Cabe destacar que o distrito de Chavantes, denominado inicialmente de Irapé, foi fundado em 1909, 1 ano após a inauguração da estação ferroviária de mesmo nome. A situação coincide com a análise feita por Monbeig (1984) na qual a chegada da ferrovia contribuía para a efetivação do núcleo urbano já existente ou influenciava na fixação de novas povoações, pois a estação ferroviária trazia trabalhadores e a necessidade de atividades comerciais que atendessem as demandas cotidianas. Também,

\footnotetext{
${ }^{1}$ Para mais informações, consultar Silva (1985).
} 
a existência da fazenda de café exigia determinados serviços e comércios que seriam atendidos pela cidade.

Na figura 2 verifica-se a expansão dos trilhos da E.F. Sorocabana. Conforme Marques (1974), a estrada de ferro Sorocabana atingiu Piraju e Manduri em 1906, Santa Cruz do Rio Pardo (ramal), Ourinhos, Chavantes, Ipaussu, Bernardino de Campos e Chavantes em 1908 e; em 1909, Salto Grande.

Figura 2: Evolução da criação das estações da E.F Sorocabana

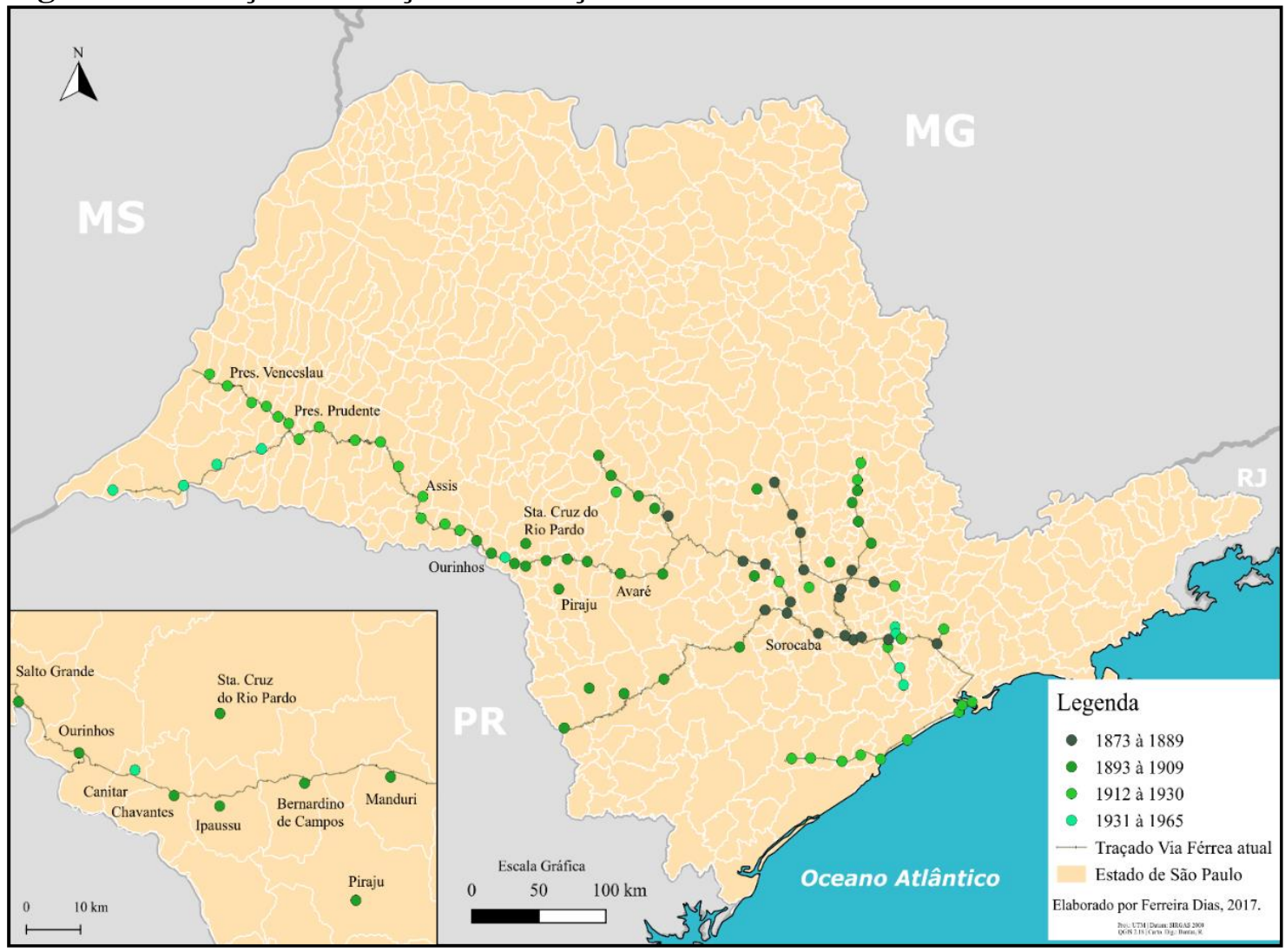

Fonte: Marques, 1974. Elaboração: a autora.

A fazenda de João Inácio da Costa Bezerra, cujo cultivo era o café, perfazia a área total do município de Chavantes, e mediante ao desenvolvimento de uma pequena povoação na mesma e da instalação de uma estação ferroviária da Sorocabana, fundou-se 
em 1909, o distrito de Chavantes, sendo parte do município de Santa Cruz do Rio Pardo até o ano de 1922 (JUNQUEIRA, 1994).

Ao tornar-se município, Chavantes também apresentou o desenvolvimento de algumas povoações em sua área rural, sendo fundado em 1935 o distrito de Irapé ${ }^{2}$, o qual permanece na mesma condição até o período atual. A outra povoação existente na área rural de Chavantes chamava-se Fortuna, uma vez que havia se desenvolvido em uma fazenda de café a qual apresentava o mesmo nome. Mediante à instalação de uma estação da ferrovia Sorocabana, no ano de 1923, a povoação Fortuna foi elevada no ano de 1944 à condição de distrito $^{3}$, porém com o nome alterado para Canitar, sendo o mesmo emancipado em 1993 (FERREIRA DIAS, 2019).

A importância dos distritos no período analisado relacionava-se à expressiva produção cafeeira nos mesmos, sendo que em suas sedes eram disponibilizados comércio e serviços necessários à essa produção. A inserção do café ocasionou a vinda de muitos trabalhadores, a fim de servirem de mão-de-obra para os recentes cafezais, levando a criação desses distritos.

O cultivo do café estendeu-se ao Centro-Oeste Paulista, e consequentemente no distrito de Chavantes, já que havia as condições físicas e econômicas nomeadamente: 1) grandes extensões de terras que poderiam ser utilizadas para o cultivo de café; 2) clima adequado, com pouca probabilidade de geadas e solo de boa qualidade; 3 ) numerosa mãode-obra, sobretudo relacionada aos migrantes de origem italiana e japonesa, recémchegados à região; 4) expansão da ferrovia Sorocabana, rumo ao oeste do estado de São Paulo, possibilitando o escoamento da produção; 5) núcleos urbanos que proporcionavam condições à efetivação da produção cafeeira, oferecendo comércio, serviços, bancos, maquinários, etc. (MONBEIG, 1984).

\footnotetext{
${ }^{2}$ Decreto 7.064 de 6-4-1935.

${ }^{3}$ Distrito criado com a denominação de Canitar (ex - povoado de Fortuna), pelo decreto-lei estadual n ${ }^{\circ}$ 14.334, de 30-11-1944, subordinado ao município de Chavantes.
} 
Para Holloway (1984), o cultivo de café era realizado em grandes fazendas, onde estabeleceu-se o regime de colonato, sendo os distritos, elementos articulados à produção. O colonato consistia em um salário pago quanto ao cultivo e colheita do café, sendo esse trabalho realizado por todos os membros da família de colonos e os trabalhos ocasionais, realizados em troca de pequenas quantidades monetárias, moradia e pequenos espaços na propriedade rural nos quais o mesmo poderia cultivar produtos para sua subsistência.

Desse modo, Santa Cruz do Rio Pardo tem sua origem no processo de desbravamento do sertão paulista, realizado por mineiros que se deslocaram, após a decadência da atividade mineradora em Minas Gerais. A partir implantação da ferrovia e expansão dos cafeeiros em direção ao Centro-Oeste Paulista, foram criados diversos distritos $^{4}$ nesse município, dentre eles Chavantes.

\section{A relação rural-urbana em Chavantes até a PRimeira METADE DO SÉCULO XX}

A gênese de Chavantes liga-se ao município de Santa Cruz do Rio Pardo, mantendo-se como distrito do mesmo até 1922, quando foi emancipado. Entre a fundação do município até o fim do século XIX, a economia baseava-se em atividades de subsistência, passando ao predomínio do café no início do século XX. O Recenseamento Geral de 1920 (BRASIL, 1920) apontava 262 estabelecimentos rurais, sendo que em 16

\footnotetext{
${ }^{4}$ Conforme Ferreira Dias (2019), Santa Cruz do Rio Pardo era formada por vários distritos. São Pedro do Turvo foi fundado em 24/12/1876 e desmembrado em 29/05/1891, tornando-se município, situação semelhante a Salto Grande fundado em 14/04/1891 e desmembrado em 27/11/1911; Óleo, fundado em 06/06/1891 e desmembrado em 14/12/1917; Chavantes, fundado em 22/10/1909 e desmembrado 04/12/1922; Bernardino de Campos, fundado em 06/12/1917 e desmembrado em 09/12/1923, mantendo o mesmo nome do período em que eram distritos. Campos Novos foi fundado em 13/04/1880 e desmembrado em 10/03/1885, tornando-se o município de Echaporã, situação semelhante a Turvo, fundado em 21/05/1934 e desmembrado em 09/1/1990, tornando-se Espírito Santo do Turvo. Os distritos de Sodrélia, fundado em 07/11/1929, Caporanga, Domélia e Clarínia, fundada em 30/11/1944, permaneceram como distritos. Por sua vez, Mandaguari foi fundado em 30/05/1905 e foi extinto na década de 1970.
}

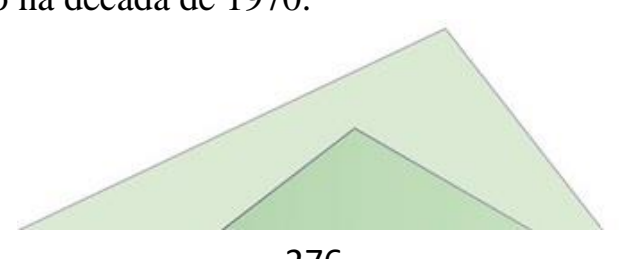


deles já havia máquinas de beneficiamento de café, apontando a importância que o café desempenharia no município.

A construção da ferrovia Sorocabana, inaugurada em 1906 no caso de Santa Cruz do Rio Pardo e em 1908 no então distrito de Chavantes, foi essencial para a expansão do café, incidindo na necessidade de mão-de-obra e, portanto, no povoamento local, o que contribuiu posteriormente para o desenvolvimento e emancipação dos distritos, a exemplo de Chavantes.

Do ponto de vista demográfico, a análise centra-se até 1920 em Santa Cruz do Rio Pardo, pois em Chavantes, há dados disponíveis apenas após a década de 1940, antes disso, Chavantes era distrito e na década de 1930 não foram realizadas pesquisas demográficas. A tabela 1 se refere aos dados demográficos de Santa Cruz do Rio Pardo até 1920 e de Chavantes, entre 1940 e 1950:

Tabela 1: Evolução populacional de Santa Cruz do Rio Pardo (1872-1920) e Chavantes (1940-1950)

\begin{tabular}{l|l|l|l}
\hline \multicolumn{3}{l}{ Santa Cruz do Rio Pardo } \\
\hline ano & População urbana & População rural & População Total \\
1872 & -------- & ------- & 3.832 \\
1890 & ------- & ------- & 5.529 \\
1900 & ------ & ------- & 4.964 \\
1920 & ------ & ---- & 39.427 \\
\hline \multicolumn{3}{l}{} \\
\hline Chavantes & População urbana & População rural & População Total \\
1940 & 2.595 & 9.132 & 11.727 \\
1950 & 2.924 & 8.946 & 11.870 \\
\hline
\end{tabular}

Fonte: IBGE (1940, 1950); BRASIL (1872, 1890, 1900, 1920).

Org: Ferreira Dias, 2019.

Conforme a tabela 1, entre 1872 e 1890, a população de Santa Cruz do Rio Pardo cresceu $30,69 \%$, reflexo do processo de migração de agricultores mineiros ao município, passando de 3.832 para 5.529 habitantes. Na década seguinte havia 4.964 habitantes, um decréscimo $11 \%$ da população, explicável devido à emancipação do distrito de São Pedro do Turvo em 1891. Em 1920 a população era de 39.427, significando um aumento na ordem de $87,40 \%$, reflexo da expansão do cultivo de café e instalação da

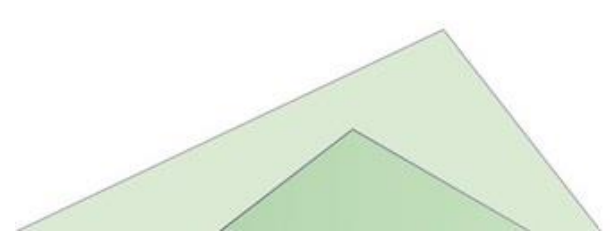


ferrovia em 1906, possibilitando o escoamento da produção cafeeira e atraindo novos contingentes populacionais, devido a oferta de trabalho nessa atividade produtiva.

A década de 1940, em escala nacional, apresentou um crescimento demográfico mostrando-se de acordo com Santos (2013), um período marcado por um aumento geral da população brasileira considerando as melhorias sanitárias, evolução da medicina quanto ao tratamento e prevenção de algumas doenças outrora mortais, bem como uma alta taxa de natalidade em especial nos últimos anos dessa década, findada a II Guerra Mundial. No entanto, a população se manteve majoritariamente rural.

Em 1940 Chavantes contava uma população de 11.727 habitantes, sendo que apenas 2.595 habitavam a cidade, revelando uma taxa de urbanização de 22,12\% (IBGE, 1940). Na década seguinte a situação pouco alterou-se, sendo 11.870 habitantes do quais 2.924 eram urbanos, significando uma taxa de urbanização de 24,63\% (IBGE, 1950). Esses dados revelam o predomínio da atividade cafeeira a qual empregava expressiva mão-de-obra no campo.

Chavantes é um município relativamente pequeno e no período analisado, décadas de 1940 e 1950, ocupava $246 \mathrm{~km}^{2}$, conforme se nota na tabela 2 :

Tabela 2: Condição do Produtor e área total dos estabelecimentos rurais de Chavantes:1940 - 1950

\begin{tabular}{l|l|l|ll}
\hline \multirow{2}{*}{ Condição do produtor } & \multicolumn{1}{|l|}{} & $\mathbf{1 9 5 0}$ & \\
\cline { 2 - 5 } & Área & $\%$ & Área & $\%$ \\
\hline Proprietários & 17.714 & $81,21 \%$ & 11.983 & $50,88 \%$ \\
Arrendatários & 4.097 & $18,78 \%$ & 653 & $2,77 \%$ \\
Ocupantes & 0 & 0 & 26 & $0,11 \%$ \\
Administradores & 0 & 0 & 10.886 & $46,22 \%$ \\
\hline Área total dos estabelecimentos (ha) & 21.811 & & 23.548 & \\
\hline
\end{tabular}

Fonte: IBGE (1940, 1950). Org: Ferreira Dias, 2019.

Conforme a tabela 2, em 1940 havia 21.811 hectares ocupados por estabelecimentos rurais $^{5}$, inexistindo a condição de ocupante e de administrador. Os

5 A condição de proprietário se refere ao indivíduo que administra terras próprias, os administradores se referem à pessoa física ou jurídica que atua como gestor do estabelecimento 
proprietários ocupavam $81,21 \%$ da área dos estabelecimentos rurais, seguido pelos arrendatários, em 18,78\%. Em 1950 havia 23.548 hectares relativos à estabelecimentos rurais, um aumento de 7,37\% em relação a 1940. Em 1940 não havia a condição de ocupante e, em 1950, havia apenas $0,11 \%$ da área total. Por outro lado, diminuiu a área utilizada pelos arrendatários, passando de 18,78\% da área total dos estabelecimentos rurais para 2,77\%. A área dos proprietários diminuiu de 17.714 hectares para 11.983, passando de $81,21 \%$ da área total dos estabelecimentos rurais, para 50,88\%.

A diminuição da quantidade numérica e da área relativa aos arrendatários não se refere a mudança dos mesmos para a condição de proprietário rural (tabela 3). Por outro lado, a condição de arrendatário não era expressiva em $1940^{6}$, pois os mesmos ocupavam 4.097 hectares (18,78\% do total), na medida que a condição de proprietário era predominante, ocupando 17.714 hectares. Em realidade a maior mudança foi a condição de administrador, que era nula em 1940 e passou a representar 46,22\% da área total ocupada ou 10.886 hectares, em 34 estabelecimentos rurais (tabela 2).

Tabela 3: Total dos estabelecimentos por condição do produtor rural em Chavantes: 1950

\begin{tabular}{l|l|l}
\hline \multirow{2}{*}{ Condição do Produtor } & $\mathbf{1 9 5 0}$ \\
\cline { 2 - 3 } & Quantidade & $\%$ \\
\hline Proprietários & 146 & $76,94 \%$ \\
Arrendatários & 9 & $4,73 \%$ \\
Ocupantes & 1 & $0,52 \%$ \\
Administradores & 34 & $17,84 \%$ \\
\hline Total de estabelecimentos & 190 \\
\hline
\end{tabular}

Fonte: IBGE (1950). Org: Ferreira Dias, 2019.

$\mathrm{Na}$ tabela 4, observa-se que Chavantes apresentou poucas alterações quanto à estrutura dimensional dos estabelecimentos rurais. Os pequenos estabelecimentos com menos de 10 hectares continuaram representando apenas 116 hectares, $0,53 \%$ do total em

agropecuário, substituindo o produtor. Os estabelecimentos arrendados são alugados para terceiros e os estabelecimentos ocupados são aqueles sem o registro definitivo.

${ }^{6}$ Não há dado disponível sobre o total de estabelecimentos por produtor quanto ao ano de 1940. 
1940 e 0,49\% em relação à 1950. Os estabelecimentos entre 10 e 50 hectares passaram de 4.096 hectares (18,91\%) em 1940, para 2.577 em 1950 ou 10,91\% do total. O patamar entre 101 e 500 hectares passou de 6.630 hectares em 1940 para 6.085 hectares, representando $30,64 \%$ e $25,77 \%$ respectivamente. Os estabelecimentos entre 500 a 1.000 hectares somavam 5.889 hectares em 1940 e passaram a ser 6.241 em 1950.

A principal alteração ocorreu quanto aos estabelecimentos rurais acima de 1.000 hectares, os quais somavam 2.365 hectares em 1940 e passaram a ser 6.931 hectares, ou 10,92\% e 29,35\% respectivamente. Associando aos dados expostos na tabela 5 , nota-se que o patamar de estabelecimentos rurais com mais de 1.000 hectares aumentou numericamente de 2 para 6, representando 0,69\% do total em 1940 e 3,12\% em 1950.

Observando os dados expostos na tabela 5, conclui-se que os pequenos estabelecimentos rurais mantiveram-se prevalentes, porém ocorreu um processo de concentração de terras na medida que os patamares dos maiores estabelecimentos rurais obtiveram aumento. Embora os estabelecimentos pequenos com tamanhos inferiores a 50 hectares representassem 63,49\% do total, em termos absolutos, isto é, em área ocupada, os mesmos ocupavam apenas $11,4 \%$ da área total dos estabelecimentos rurais. Considerando o fato da área relativa aos administradores, exposta na tabela ter aumentado significativamente, estima-se que os mesmos relacionam-se ao aumento da área referente aos estabelecimentos rurais de maior tamanho.

Tabela 4: Estrutura Dimensional Estabelecimentos Rurais em Chavantes:1940-1950

\begin{tabular}{|c|c|c|c|c|}
\hline \multirow{2}{*}{$\begin{array}{l}\text { Grupos de } \\
\text { Área }\end{array}$} & \multicolumn{2}{|l|}{1940} & \multicolumn{2}{|l|}{1950} \\
\hline & Área (ha) & $\%$ & Área (ha) & $\%$ \\
\hline Menos de 10 & 116 & $0,53 \%$ & 116 & $0,49 \%$ \\
\hline 10 a 50 & 4.096 & $18,92 \%$ & 2.577 & $10,91 \%$ \\
\hline 51 a 100 & 2.542 & $11,74 \%$ & 1.659 & $7,02 \%$ \\
\hline 101 a 500 & 6.630 & $30,64 \%$ & 6.085 & $25,77 \%$ \\
\hline de 500 a 1.000 & 5.889 & $27,21 \%$ & 6.241 & $26,43 \%$ \\
\hline Mais de 1.000 & 2.365 & $10,92 \%$ & 6.931 & $29,35 \%$ \\
\hline Total & \multicolumn{2}{|l|}{21.638} & \multicolumn{2}{|l|}{23.609} \\
\hline
\end{tabular}

Fonte: IBGE (1940, 1950). Org: Ferreira Dias, 2019. 
Tabela 5: Quantidade de Estabelecimentos Rurais de Chavantes quanto à Estrutura Dimensional: entre 1940-1950

\begin{tabular}{|c|c|c|c|c|}
\hline \multirow{2}{*}{$\begin{array}{l}\text { Grupos de } \\
\text { Área }\end{array}$} & \multicolumn{2}{|l|}{1940} & \multicolumn{2}{|c|}{1950} \\
\hline & Qtde & $\%$ & Qtde & $\%$ \\
\hline Menos de 10 & 38 & $13,14 \%$ & 16 & $8,33 \%$ \\
\hline 10 a 50 & 173 & $59,86 \%$ & 104 & $54,16 \%$ \\
\hline 51 a 100 & 36 & $12,45 \%$ & 25 & $13,02 \%$ \\
\hline 101 a 500 & 31 & $10,72 \%$ & 32 & $16,66 \%$ \\
\hline de 500 a 1.000 & 9 & $3,11 \%$ & 9 & $4,68 \%$ \\
\hline Mais de 1.000 & 2 & $0,69 \%$ & 6 & $3,12 \%$ \\
\hline Total & \multicolumn{2}{|l|}{289} & \multicolumn{2}{|l|}{192} \\
\hline
\end{tabular}

Fonte: IBGE (1940, 1950). Org: Ferreira Dias, 2019.

De acordo com a tabela 6, entre 1940 e 1950 não ocorreram mudanças significativas quanto à área ocupada por cultivos agrícolas em Chavantes, sendo 13.022 hectares ou 59,70\% do total em 1940 e, 13.963 hectares ou 59,29\% da área total em 1950. A agricultura era o principal uso da terra tanto em 1940 quanto em 1950.

As pastagens aumentaram quanto à área utilizada em Chavantes, perfazendo 3.510 hectares, ou 16,09\% em 1940. Porém, o Censo Agrícola de 1940 demonstrou uma evolução quanto à área utilizada e participação percentual, sendo 4.542 hectares, ou 19,29\% respectivamente. Em termos de área utilizada, ocorreu um aumento de 22,72\%. Entretanto, o aumento na quantidade de animais foi de 40,56\%, uma vez que em 1940 havia 4.814 animais, dentre equinos, muares, caprinos e principalmente bovinos e em 1950 havia 8.100 animais (IBGE, 1940).

A área relativa às matas passou de 3.212 hectares em 1940 para 2.200 hectares em 1950 , ou $14,72 \%$ e 9,34\% respectivamente. A diminuição da área relativa às matas, em termos reais, foi de $31,50 \%$. Estima-se que parte dessas matas foi transformada em pastagens, na medida que à área destinada a agricultura aumentou 14,90\%, entre $1940 \mathrm{e}$ 1950. Por sua vez, as áreas não utilizadas, 1.724 hectares ou 7,90\% em 1940, diminuíram

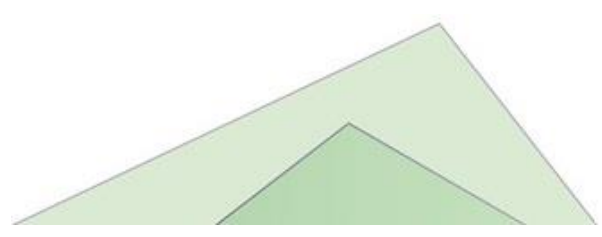


para 1.546 hectares ou 6,56\% em 1950. A diminuição real foi de $11,41 \%$, sendo áreas possivelmente incorporadas pelas pastagens.

Por outro lado, no período analisado houve um aumento de 954 hectares, ou $73,55 \%$ em área improdutiva, tratando-se possivelmente do exaurimento do solo em decorrência do plantio do café, pois esse gênero agrícola era predominante em 1940 e também em 1950, conforme nota-se na tabela 7.

Tabela 6: Utilização das terras em Chavantes:1940 - 1950

\begin{tabular}{|c|c|c|c|c|}
\hline \multirow[t]{2}{*}{ Atividade } & \multicolumn{2}{|l|}{1940} & \multicolumn{2}{|l|}{1950} \\
\hline & Área (ha) & Total (\%) & Área (ha) & Total (\%) \\
\hline Agricultura & 13.022 & $59,70 \%$ & 13.963 & $59,29 \%$ \\
\hline Pastagens & 3.510 & $16,09 \%$ & 4.542 & $19,29 \%$ \\
\hline Matas e florestas & 3.212 & $14,72 \%$ & 2.200 & $9,34 \%$ \\
\hline Não utilizadas & 1.724 & $7,90 \%$ & 1.546 & $6,56 \%$ \\
\hline Improdutivas & 343 & $1,57 \%$ & 1.297 & $5,50 \%$ \\
\hline Total & \multicolumn{4}{|c|}{23.548} \\
\hline
\end{tabular}

Fonte: (IBGE, 1940, 1950). Org: Ferreira Dias, 2019.

A tabela 7 apresenta os principais cultivos agrícolas em Chavantes e, embora a cana-de-açúcar ainda não tivesse importância no âmbito municipal, fato que ocorreu somente após a década de 1970, optou-se por relacionar sua produção também em 1940 e 1950. Em 1950, eram destinados 19 hectares ao cultivo de cana-de-açúcar e a produção era 544 toneladas, o que representava $0,17 \%$ da área municipal e $4,11 \%$ do total produzido. O feijão não apresentou alterações quanto a quantidade produzida e possivelmente quanto à área destinada ao mesmo.

O milho ocupava a segunda colocação entre os cultivos pois a produção representava 33,66\% do total produzido em 1940. Em 1950, o milho somava a segunda maior área destinada a um cultivo, 1.357 hectares, o que representava 12,68\%. A quantidade produzida em 1950, 3.270 toneladas, representava $24,75 \%$, a segunda colocação nesse quesito. Entretanto, a participação do milho no total produzido reduziuse entre 1940 e 1950 em $3,90 \%$.

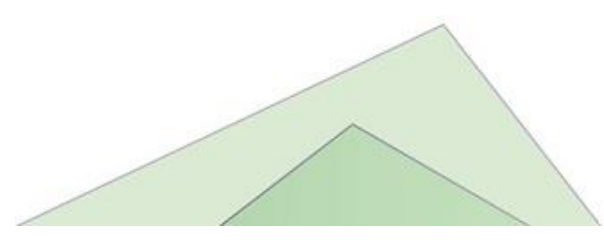


Porém, uma das maiores mudanças quanto aos principais cultivos ocorreu em relação ao algodão. Em 1940 foram produzidas 1.183 toneladas de algodão, o que representava 10,93\% do total. Em 1950, a produção foi de apenas 75 toneladas em 185 hectares, o que significava $0,56 \%$ da produção total, efetuada em $1,7 \%$ da área total. Entre 1940 e 1950 a produção diminuiu 93,66\% deixando de ser um elemento importante na economia de Chavantes. Quanto ao arroz, observa-se um crescimento em relação à quantidade produzida de 83,68\%, passando de 160 toneladas em 1940 para 673 toneladas produzidas em 1950.

A principal atividade econômica em Chavantes permaneceu o cultivo de café, ocupando a maior área dentre todos os cultivos em 1950; 8.727 hectares ou 81,53\% da área total. A quantidade produzida também aumentou, passando de 5.344 toneladas em 1950 ou $49,35 \%$ do total, para 8.534 toneladas em 1950 , significando $66,22 \%$ do total.

Tabela 7: Área e quantidade produzida dos principais cultivos agrícolas de Chavantes: 1940 - 1950

\begin{tabular}{l|l|l|l|l}
\hline \multirow{2}{*}{ Principais Culturas } & \multicolumn{1}{|l|}{$\mathbf{1 9 4 0}$} & $\mathbf{1 9 5 0}$ & \\
\cline { 2 - 5 } & Área(ha) & Qtde (T) & Área(ha) & Qtde (T) \\
\hline Café & ----- & 5.344 & 8.727 & 8.534 \\
Algodão & ---- & 1.183 & 185 & 75 \\
Arroz & ---- & 160 & 374 & 673 \\
Milho & ---- & 3.403 & 1.357 & 3.270 \\
Feijão & ---- & 180 & 39 & 115 \\
Cana-de-açúcar & ----- & 550 & 19 & 544 \\
\hline Área total dos principais & ------ & 10.820 & 10.701 & 13.211 \\
produtos agrícolas & & & & \\
\hline
\end{tabular}

Fonte: IBGE (1940, 1950). Org: Ferreira Dias, 2019.

No período analisado, Chavantes pautou sua economia, sobretudo no cultivo de café. A presença da ferrovia facilitava o escoamento da produção cafeeira e, associada à presença de mão-de-obra e das condições físicas necessárias, propiciou o êxito desse cultivo nesse município. O sistema de trabalho em colonato, ainda existente no período, trazia como consequência o consumo e a venda dos excedentes da produção desenvolvida pelos colonos, favorecendo o desenvolvimento do comércio na cidade. Embora as

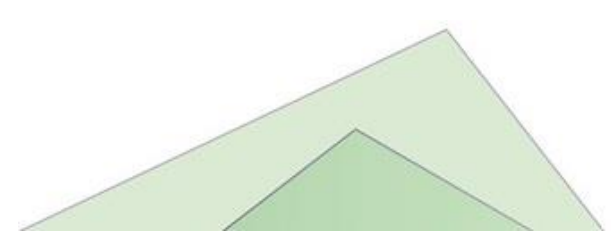


atividades econômicas desenvolvidas no âmbito rural fossem predominantes na economia municipal de Chavantes, havia atividades econômicas desenvolvidas no âmbito urbano.

Durante as décadas de 1940 e 1950, Chavantes tinha o predomínio da população rural, não apresentava um setor industrial expressivo, sendo a economia pautada no setor primário.

Assim, em 1940 havia em Chavantes 10 estabelecimentos industriais, os quais empregavam 43 pessoas. Em 1950 houve um aumento de 60,55\% quanto à quantidade de pessoas empregadas e 75,60\% em relação ao número de empresas. Em consulta ao censo industrial de 1940 e 1950, verificou-se que as indústrias existentes relacionavam-se aos alimentos, materiais metálicos, beneficiamento de café e confecção de roupas e calçados. Quanto ao comércio varejista, em 1940 havia em Chavantes, 59 estabelecimentos comerciais os quais empregavam 89 pessoas, ao passo que em 1950 havia 57 estabelecimentos comerciais, empregando 78 pessoas, ou seja, um decréscimo de 3,5\% e $14,10 \%$ respectivamente (IBGE, 1940, 1950).

Em 1940, no comércio atacadista havia 12 empresas e 23 pessoas empregadas. Na década de 1950, 1 estabelecimento com 4 pessoas empregadas, ou seja, Chavantes apresentou decréscimo quanto aos itens citados, na medida que houve redução de $91,66 \%$ dos estabelecimentos de comércio atacadista e $82,60 \%$ em relação ao pessoal empregado. A existência de um comércio atacadista possibilitava a distribuição dos produtos industrializados, necessários à produção agrícola e também ao abastecimento da população, quanto às suas necessidades básicas. Portanto, tal atividade econômica atrelava-se ao setor primário, denotando que as atividades econômicas urbanas subsidiavam aquelas que ocorriam no âmbito rural (FERREIRA DIAS, 2019).

\section{CONSIDERAÇÕES FINAIS}

A gênese de Chavantes esteve estritamente relacionada à implantação da ferrovia e expansão dos cafeeiros em direção ao Centro-Oeste Paulista. A cafeicultura 
demandava numerosa mão-de-obra e, associado a um sistema de colonato, contribuiu para o povoamento e desenvolvimento desse município.

Durante o período analisado, a economia municipal era fortemente atrelada ao cultivo de café e a sede urbana era pouco povoada e sem destaque quanto as atividades econômicas, as quais atendiam as demandas do campo. Exemplo disso foi apontado por Corrêa (2001), para o qual a pequena importância do setor do comércio nas pequenas cidades até a década de 1950 ocorria porque a pequena cidade disponibilizava em geral, itens que atendiam sobretudo às atividades agrícolas pois à população demandava poucos serviços, ou utilizava serviços informais.

As atividades econômicas realizadas na cidade atendiam à demanda do âmbito rural, sendo que as atividades agrícolas, ainda empregavam vasta mão-de-obra, uma vez que ainda não haviam passado por uma modernização expressiva, justificando assim, o predomínio da população habitando a área rural. Porém, a evidente concentração de terras observada entre 1940 e 1950 denotava mudanças nessa dinâmica, na medida que nas décadas posteriores ocorreria a intensificação do processo de urbanização nesse município e a expansão do cultivo da cana-de-açúcar, presentemente a principal atividade agrícola municipal.

A existência de um comércio atacadista possibilitava a distribuição dos produtos industrializados, necessários à produção agrícola e também ao abastecimento da população, quanto às suas necessidades básicas. Portanto, tal atividade econômica atrelava-se ao setor primário, denotando que as atividades econômicas urbanas subsidiavam aquelas que ocorriam no âmbito rural. O comércio varejista atendia as demandas oriundas do campo e que não eram atendidas nos distritos, concentrando-se na sede urbana municipal.

A relação rural-urbana perpassava pelo predomínio de uma economia pautada na agricultura, cujo principal produto referia-se ao café, item voltado para a comercialização fora do âmbito local e outras produções direcionadas para o consumo local. Os núcleos urbanos colocavam-se como apoio às necessidades de consumo da 
população rural e uma restrita população urbana, bem como atendiam a demanda quanto ao beneficiamento dos produtos agrícolas e comercialização dos alimentos produzidos localmente.

\section{REFERÊNCIAS}

ALVES, F. D; VALE, A.R. A relação campo-cidade e suas leituras no espaço. Boa Vista: Acta Geográfica, edição especial de Geografia Agrária, p.33-41, 2013.

BRASIL. Censo Demográfico de 1890. Rio de Janeiro, Oficina da Estatística, 1895.

BRASIL. Recenseamento Geral de 1872. Rio de Janeiro, v.12, 1874. Disponível em: <https://biblioteca.ibge.gov.br/visualizacao/livros/liv25477_v12_sp.pdf>. Acesso em 23 de março de 2020.

BRASIL. Recenseamento de 1900. Rio de Janeiro, Oficina da Estatística, 1901.

BRASIL. Recenseamento de 1920. Rio de Janeiro: Oficina da Estatística, 1925.

CANDIDO, A. Os parceiros do Rio Bonito. Rio de Janeiro: São Paulo: Livraria duas cidades, $1979,284 \mathrm{p}$.

CANO, W. Desconcentração Produtiva Regional do Brasil: 1970-2005. São Paulo: Editora Unesp, 2007, 304 p.

CORRÊA, R. L. Trajetórias Geográficas. Rio de Janeiro: Bertrand Brasil, 2001.

FERREIRA DIAS, F. Pequenas Cidades na Rede Urbana de Ourinhos - SP: Agronegócio e Especialização Produtiva. Tese (Doutorado em Geografia). Universidade Estadual de Londrina, Londrina, 300p, 2019. Disponível em:

<http://www.bibliotecadigital.uel.br/document/?code=vtls000228452>. Acesso em 10 de maio de 2020.

HOLLOWAY, T. H. Imigrantes para o café: café e sociedade em São Paulo 1886-1934. Rio de Janeiro: Paz e Terra, 1984.

IBGE. Contagem da população, 2018. Disponível em:

<http:/www.sidra.ibge.gov.br>. Acesso 12 em maio de 2020.

IBGE. Dados censitários 1940 a 2000. Disponível em:

<http:/www.sidra.ibge.gov.br>. Acesso em 19 maio de 2020.

JUNQUEIRA, M. F. Santa Cruz do Rio Pardo: Memórias-subsídios para a história de uma cidade paulista. São Paulo: Editora Viena, 1994, 342 p. 
MARQUES, F. de A. As ferrovias de São Paulo: Paulista, Mogiana e Sorocabana (1870- 1940). Dissertação (Mestrado) Universidade de São Paulo, São Paulo; 1974.

MONBEIG, P. Pioneiros e fazendeiros de São Paulo. São Paulo: Editora Pólis Editora Hucitec, $1984,392 \mathrm{p}$

PRADO, C. J. Formação Econômica do Brasil Contemporâneo. São Paulo: Brasiliense, 1999.

PRADO, C. Santa Cruz do Rio Pardo: historiografia para o século XIX. Santa Cruz do Rio Pardo: Edição dos autores, 2012, 457 p.

SANTOS, M. A urbanização brasileira. São Paulo: Hucitec, 2013, 176 p.

SEADE. Rede urbana e regionalização do Estado de São Paulo. São Paulo: Emplasa, 2011. Disponível em:

<http://www.seade.gov.br/produtos/publicacoes/pub_RedeUrbanaRegionalizacaoESP_2011.pdf $>$ Acesso em 12/08/2020.

SILVA, S. Expansão cafeeira e origens da indústria no Brasil. São Paulo: Alfa-Omega, 1985, $120 \mathrm{p}$.

WAIBEL, L. As zonas pioneiras do Brasil. Rio de Janeiro: Revista Brasileira de Geografia, v. 18, n. 4, p.389-422, 1955.

Recebido em abril de 2020.

Revisado em setembro de 2020.

Aceito para publicação em novembro de 2020. 